Article

\title{
Environmental Remediation of Toxic Organic Pollutants Using Visible-Light-Activated $\mathrm{Cu} / \mathrm{La} / \mathrm{CeO}_{2} / \mathrm{GO}$ Nanocomposites
}

\author{
Dhanapal Vasu ${ }^{1,+}$, Yongsheng Fu ${ }^{2,+}$, Arjunan Karthi Keyan ${ }^{1}$, Subramanian Sakthinathan ${ }^{1, *}$ and Te-Wei Chiu ${ }^{1, *(D)}$ \\ 1 Department of Materials and Mineral Resources Engineering, National Taipei University of Technology, \\ No. 1, Section 3, Chung-Hsiao East Road, Taipei 106, Taiwan; dvasukalyan@gmail.com (D.V.); \\ karthikeyan100596@gmail.com (A.K.K.) \\ 2 Key Laboratory for Soft Chemistry and Functional Materials, Nanjing University of Science and Technology, \\ Nanjing 210094, China; fuyongsheng@njust.edu.cn \\ * Correspondence: sakthinathan1988@gmail.com (S.S.); tewei@ntut.edu.tw (T.-W.C.) \\ + These authors contributed equally.
}

check for updates

Citation: Vasu, D.; Fu, Y.; Keyan, A.K.; Sakthinathan, S.; Chiu, T.-W. Environmental Remediation of Toxic Organic Pollutants Using Visible-Light-Activated $\mathrm{Cu} / \mathrm{La} / \mathrm{CeO}_{2} / \mathrm{GO}$ Nanocomposites. Materials 2021, 14, 6143. https:// doi.org/10.3390/ma14206143

Academic Editor: Alexander N. Obraztsov

Received: 3 September 2021

Accepted: 12 October 2021

Published: 16 October 2021

Publisher's Note: MDPI stays neutral with regard to jurisdictional claims in published maps and institutional affiliations.

Copyright: (c) 2021 by the authors. Licensee MDPI, Basel, Switzerland. This article is an open access article distributed under the terms and conditions of the Creative Commons Attribution (CC BY) license (https:/ / creativecommons.org/licenses/by/ $4.0 /)$.
Abstract: Environmental pollution is a major threat that increases day by day due to various activities. A wide variety of organic pollutants enter the environment due to petrochemical activities. Organic contamination can be unsafe, oncogenic, and lethal. Due to environmental issues worldwide, scientists and research communities are focusing their research efforts on this area. For the removal of toxic organic pollutants from the environment, photocatalysis-assisted degradation processes have gained more attention than other advanced oxidation processes (AOPs). In this manuscript, we report a novel photocatalysis of copper and lanthanum incorporating cerium oxide $\left(\mathrm{CeO}_{2}\right)$ loaded on graphene oxide $\left(\mathrm{Cu} / \mathrm{La} / \mathrm{CeO}_{2} / \mathrm{GO}\right)$ nanocomposites successfully synthesized by hydrothermal techniques. XRD results showed the presence of dopant ions and a crystalline structure. FESEM images showed that the surface morphology of the synthesized nanocomposites formed a rodlike structure. The highlight of this study is the in-situ synthesis of the novel $\mathrm{Cu} / \mathrm{La} / \mathrm{CeO}_{2} / \mathrm{GO}$ nanocomposites, which manifest higher photodegradation of harmful organic dyes (Rhodamine B (RhB), Sunset Yellow (SY), and Cibacron Red (CR)). In $\mathrm{Cu} / \mathrm{La} / \mathrm{CeO}_{2} / \mathrm{GO}$ nanocomposites, the dopant materials restrict the rapid recombination of photoinduced electron-hole pairs and enhance the photocatalytic activity. The degradation percentages of RhB, SY, and CR dye solution are $80 \%$, $60 \%$, and $95 \%$, respectively. In summary, the synthesized nanocomposites degrade toxic organic dyes with the help of visible light and are suitable for future industrial applications.

Keywords: visible light; degradation; wastewater; Rhodamine B; sunset yellow; cibacron red; nanocomposites

\section{Introduction}

Every living organism in the world depends on water. Moreover, only a small percentage of the freshwater in the world is available for drinking and agriculture [1]. However, the rapid growth of human activities, such as urbanization and industrialization, has had a major impact on water resources. Industries such as the textile, leather, paper, medical, pulp, and dyeing industries release their effluent into water resources without any purification, causing water pollution [1-3]. A higher amount of wastewater is generated by the textile industry than by other industries. Effluent from the textile industry contains a wide variety of dyes, which make the water colored, toxic, and carcinogenic for all living organisms. During the dyeing process, 1-20\% of the dye is lost, and it is directly disposed of in water resources [4-6]. This wastewater contains high amounts of anthraquinone and azo and heteropoly aromatic dyes. Among the textile dyes, azo dyes are a special class of dye and are widely used, constituting $60-70 \%$ of all dye products [2,7-10]. Azo dyes are classified by their aromatic compounds, which include one or more azo groups $(-\mathrm{N}=\mathrm{N}-)$. 
Therefore, the wastewater from that industry is highly harmful to human and aquatic life because the waste products have serious impacts on the environment [10-12].

To develop suitable techniques for the degradation and mineralization of dye-polluted wastewater, many techniques are applied to degrade dye effluent, as follows: (1) physical methods, such as membrane filtration, flotation, and sedimentation; (2) biological methods; and (3) chemical methods, such as chemical coagulation, photocatalysis, Fenton or Fentonlike oxidation, and ozone $\left(\mathrm{O}_{3}\right)$ oxidation processes [13-15]. Although those treatment methods have some advantages, they cannot fully degrade organic contaminants in industrial wastewater [16]. Among the emerging techniques for textile effluent decontamination, advanced oxidation processes (AOPs) are capable of mineralizing non-biodegradable and toxic organic compounds $[9,16,17]$. AOPs are generally based on the in situ generation of more active reactive species $\left(\mathrm{OH}^{\bullet}, \mathrm{H}_{2} \mathrm{O}_{2}, \mathrm{O}_{3}, \mathrm{O}_{2}\right.$, and $\left.\mathrm{O}_{2}{ }^{\bullet-}\right)$ [12,18]. In AOPs, the oxidation process is primarily responsible for the removal of textile effluents. In recent decades, metal oxide nanoparticles have attracted research efforts due to their high photocatalytic activity and stability. Particularly, nano-sized ceria $\left(\mathrm{CeO}_{2}\right)$ photocatalysis for the oxidation of organic compounds has intrinsic advantages over other types of photocatalysis because of its properties [19]. Ceria is a ceramic material used in fields such as fuel cells, gas sensors, phosphors, polishing materials, energy storage devices, and catalysis.

For these applications, the research community constantly seeks to enhance the physicochemical properties of ceria to attain better performance. Ceria is an emerging photocatalyst for dye wastewater treatment, and it has a bandgap of 3.2-3.4 eV, which is similar to the bandgap of $\mathrm{TiO}_{2}[20,21]$. Hence, ceria can be significantly enhanced by tuning the bandgap, size, interface, and surface structure via doping with trivalent and divalent cations in the crystal lattice. The reduction capability of ceria, from the $\mathrm{Ce}^{4+}$ ionic state to $\mathrm{Ce}^{3+}$ with the incorporation of oxygen vacancies, makes it a strong contender for use as a catalyst or photocatalyst. Copper oxide $(\mathrm{CuO})$ is a narrow-bandgap $(1.2 \mathrm{eV})$ p-type semiconductor material that shows excellent catalytic properties [22-24]. The incorporation of copper ions into the fluorite-type crystal structure of ceria can enhance its properties, such as the oxygen storage capacity, sintering temperature, and photocatalytic activity. A synergetic effect between $\mathrm{Cu}^{+} / \mathrm{Cu}^{2+}$ and $\mathrm{Ce}^{3+} / \mathrm{Ce}^{4+}$ results in higher interfacial redox activity, and at the same time, the catalytic ability of $\mathrm{Cu}$-doped $\mathrm{CeO}_{2}$ is changed or enhanced [25]. Moreover, the important trivalent metal ions that are generally considered include $\mathrm{Sm}^{3+}$, $\mathrm{Eu}^{3+}, \mathrm{Sc}^{3+}, \mathrm{Gd}^{3+}$, and $\mathrm{La}^{3+}$, among others. $\mathrm{La}^{3+}$ has important applications in various fields, particularly in electronic devices, photocatalysis, and optical and solid oxide fuel cells. When trivalent La ions are doped into the ceria crystal lattice, the $\mathrm{La}^{3+}$ ions replace $\mathrm{Ce}^{4+}$ ions and create a charge imbalance, which introduces oxygen vacancies into the surface of the material. These surface defects are mainly responsible for the improvement of the photocatalytic properties of the photocatalyst. Moreover, an efficient strategy is to deposit the photocatalysts on conducting substrates to enhance the conductivity and dispersibility [26-29].

Graphene, as a two-dimensional, hexagonal, single-layered carbon, has attracted attention to non-metal catalysts. Anchoring $\mathrm{Cu} / \mathrm{La} / \mathrm{CeO}_{2}$ catalysts on graphene is an important solution for engineering the photocatalytic activity of $\mathrm{Cu} / \mathrm{La} / \mathrm{CeO}_{2}$. To the best of our knowledge, no $\mathrm{Cu} / \mathrm{La} / \mathrm{CeO}_{2} / \mathrm{GO}$-related photocatalytic application has been achieved under visible light to date. In this study, we synthesized $\mathrm{Cu} / \mathrm{La} / \mathrm{CeO}_{2} / \mathrm{GO}$ nanocomposites through hydrothermal techniques. The photocatalytic ability of the synthesized nanocomposites was studied using three different organic dyes (RhB, SY, and CR) under irradiation with visible light. The role of reactive radicals was studied with the help of free radical scavenging techniques. A possible degradation reaction mechanism for RhB, SY, and $\mathrm{CR}$ dyes was explored to illustrate the reaction involved in photocatalysis. The results revealed that $\mathrm{Cu} / \mathrm{La} / \mathrm{CeO}_{2} / \mathrm{GO}$ nanocomposites have a high potential for degradation of organic compounds under visible-light irradiation. 


\section{Materials and Methods}

Cerium (III) nitrate hexahydrate $\left(\mathrm{Ce}\left(\mathrm{NO}_{3}\right)_{3.6} \mathrm{H}_{2} \mathrm{O}\right)$, copper (II) nitrate trihydrate $\left(\mathrm{CuH}_{6} \mathrm{~N}_{2} \mathrm{O}_{9}\right)$, lanthanum (III) nitrate hexahydrate $\left(\mathrm{La}\left(\mathrm{NO}_{3}\right)_{3.6} \mathrm{H}_{2} \mathrm{O}\right)$, and sodium hydroxide $(\mathrm{NaOH})$ were purchased from Sigma-Aldrich, Taiwan. Any other modifications and purifications were allowed for these materials. Moreover, double-distilled (DI) water was used in all experiments.

\subsection{Synthesis of Graphene Oxide (GO)}

Modified Hummers' preparation techniques were used to prepare the graphene oxide (GO) [30]. In this experiment, $10 \mathrm{~g}$ of graphite powder was introduced into concentrated sulfuric acid $(100 \mathrm{~mL})$ with $2 \mathrm{~g}$ of sodium nitrate and stirred in an ice-water bath to control the solution temperature. Then, $5 \mathrm{~g}$ of potassium permanganate was added to the above mixture, and the temperature of the solution was held at $20^{\circ} \mathrm{C}$ until the mixture turned green. The mixed solution was transferred to another water bath with a temperature of $35^{\circ} \mathrm{C}$, and $400 \mathrm{~mL}$ of DI water and $20 \mathrm{~mL}$ of hydrogen peroxide solution were added to the solution before it was stirred for $1 \mathrm{~h}$ to extract potassium permanganate. Finally, the solution was washed and cleaned with DI water several times. The cleaned GO solution was dried and heated in a hot-air oven at $90^{\circ} \mathrm{C}$ for $24 \mathrm{~h}$.

\subsection{Synthesis of $\mathrm{Cu} / \mathrm{La} / \mathrm{CeO}_{2} / \mathrm{GO}$ Nanocomposites}

Hydrothermal techniques were used to synthesize $\mathrm{Cu} / \mathrm{La} / \mathrm{CeO}_{2} / \mathrm{GO}$ composites. Equal (0.1) molar ratios of copper, cerium, and lanthanum precursor were placed into separate beakers containing $20 \mathrm{~mL}$ of DI water. Those solutions were simultaneously stirred magnetically for 30 min to obtain homogenous mixtures. After that, the copper and lanthanum solutions were added dropwise into the cerium solution under magnetic stirring, and $0.2 \mathrm{M} \mathrm{NaOH}$ solution was added as a reducing agent. The mixed solution was steadily stirred for $1 \mathrm{~h}$ at ambient temperature. After stirring, $100 \mathrm{mg}$ of reduced graphene oxide was added to the above solution, which was further stirred for $1 \mathrm{~h}$ The resulting composite solution was transferred to a statin-less, steel-lined autoclave and then heated in a hot-air oven at $120^{\circ} \mathrm{C}$ for $12 \mathrm{~h}$. After the hydrothermal process, the autoclave was cooled naturally at room temperature. The $\mathrm{Cu} / \mathrm{La} / \mathrm{CeO}_{2} / \mathrm{GO}$ composites were centrifuged and washed with DI water and ethanol several times, and then the obtained composites were dried in an oven at $90^{\circ} \mathrm{C}$ for $24 \mathrm{~h}$. The obtained powder composites were calcinated at $600{ }^{\circ} \mathrm{C}$ for $3 \mathrm{~h}$. The crystalline structure, surface morphology, functional groups, and elemental surface chemistry of the synthesized composites were characterized by methods such as $\mathrm{X}$-ray diffractometry (XRD) and field-emission scanning electron microscopy (FE-SEM).

\subsection{Characterization of $\mathrm{Cu} / \mathrm{La} / \mathrm{CeO}_{2} / \mathrm{GO}$ Nanocomposites}

The hydrothermally prepared nanocomposites were characterized with various techniques. The diffraction patterns of the nanocomposite were observed using $\mathrm{X}$-ray diffraction (XRD, D2 Phaser, Bruker, CuK $\alpha$ radiation $(\lambda=1.54 \AA)$ ). The surface structure and topography were obtained with a field-emission scanning electron microscope equipped with an energy-dispersive $X$-ray spectroscope ((FESEM-EDX, JEOL, JSM-7610F, Tokyo, Japan), and (Hitachi Regulus 8100, JEOL JPS-9030, AlK $\alpha$, Tokyo, Japan)), and by transmission electron microscopy (TEM, JEM-2100F, JEOL, Tokyo, Japan). In addition, the degradation of wastewater polluted with organic compounds was analyzed with a UV-visible spectrophotometer (SHIMADZU, UV-2600, Kyoto, Japan).

\subsection{Photocatalytic Activity}

The photocatalytic performance of the hydrothermally synthesized nanocomposites in the degradation of three different organic dyes, namely, RhB, SY, and CY, (Figure 1) under visible-light irradiation was studied. The three different organic dyes were prepared with concentrations of $10^{-4}$ moles. A $50 \mathrm{~W}$ tungsten-halogen lamp (340-850 nm, UV to NIR) was used as the visible-light source. For the degradation process, $100 \mathrm{~mL}$ of dye solution 
was irradiated under visible light. For this experiment, $20 \mathrm{mg}$ of nanocomposites was added to the dye solution, which was constantly stirred. Before the experiment, the dye solution with a catalyst added was stirred continuously at 30 min under the dark condition to acquire an adsorption-desorption equilibrium condition. The solution mixture was irradiated with visible light for $90 \mathrm{~min}$ under magnetic stirring, and every $10 \mathrm{~min}, 5 \mathrm{~mL}$ of the solution was extracted for the study of the degradation/decolorization of dye with a UV-visible spectrometer. Before the absorbance analysis, the extracted samples were filtered using Whatman filter paper to remove the photocatalyst.<smiles>CCN(CC)c1ccc2c(-c3ccccc3C(=O)O)c3ccc(=[N+](CC)CC)cc-3oc2c1</smiles>

Rhodamine-B<smiles>O=S(=O)(O[Na])c1ccc(/N=N/c2c(O)ccc3cc(S(=O)(=O)O[Na])ccc23)cc1</smiles>

Sunset Yellow<smiles>CO[N+]([O-])(O)c1ccc(Nc2nc(Cl)nc(Nc3ccc(S(=O)(=O)O[Na])c(N=Nc4c(S(=O)(=O)O)cc5cc(S(=O)(=O)O[Na])cc(NC(=O)c6ccccc6)c5c4O)c3)n2)cc1</smiles>

\section{Cibacron Red}

Figure 1. Chemical structure of three different dyes.

\section{Results and Discussion}

\subsection{Study of the Crystalline Structure}

The XRD patterns of the hydrothermally synthesized $\mathrm{Cu} / \mathrm{La} / \mathrm{CeO}_{2} / \mathrm{GO}$ nanocomposites are depicted in Figure 2. The diffraction peaks of $\mathrm{CuO}$ were attributed to the (-110), (111), (-112), (-202), (020), (202), (-113), (022), (311), and (004) planes, which indicated the monoclinic structure of $\mathrm{CuO}$ crystals (JCPDS: 01-089-5895). The peaks due to $\mathrm{CeO}_{2}$ also indicated the (111), (200), and (220) planes, which were attributed to the cubic fluorite-structured $\mathrm{CeO}_{2}$ crystals (JCPDS: 03-065-0859) [19-22]. In addition, $\mathrm{La}_{2} \mathrm{O}_{3}$-related peaks were attributed to the (002), (011), and (003) planes, which were indexed to the hexagonal structure of $\mathrm{La}_{2} \mathrm{O}_{3}$ crystals (JCPDS: 01-083-1349) [23-26]. The GO-related peaks also presented $2 \theta$ at $22.74^{\circ}$. These results indicated that the dopant ions were successfully doped into the ceria lattice structure due to the differences between the ionic radii of the $\mathrm{Cu}^{2+}(77 \mathrm{pm}), \mathrm{La}^{3+}(103 \mathrm{pm})$, and $\mathrm{Ce}^{4+}(102 \mathrm{pm})$ ions, respectively. 


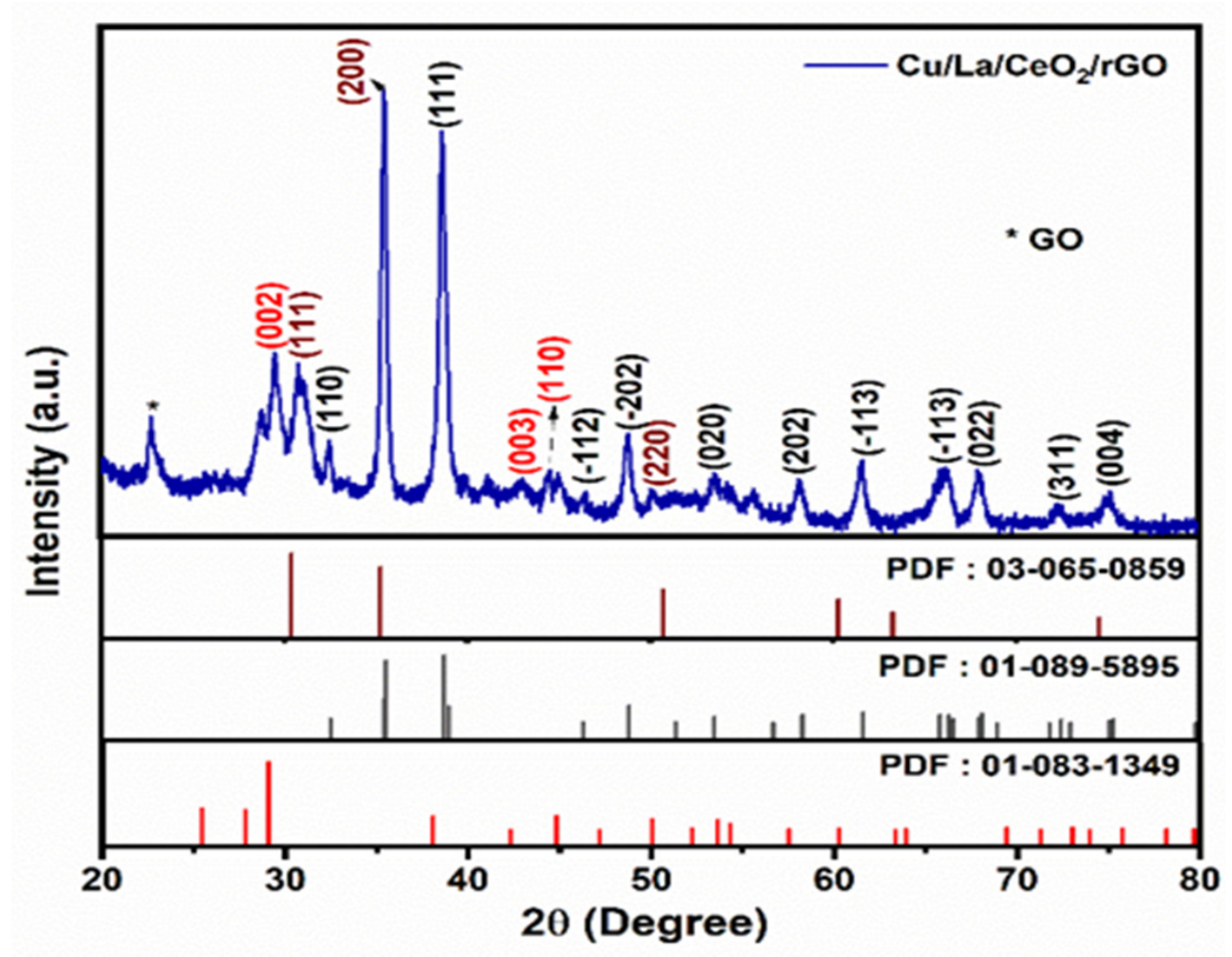

Figure 2. XRD analysis of $\mathrm{Cu} / \mathrm{La} / \mathrm{CeO}_{2} / \mathrm{GO}$ nanocomposites.

The nanocomposite crystalline size was also calculated using Scherrer's equation:

$$
\mathrm{D}=\mathrm{k} \lambda /\left(\beta_{(1 / 2)} \cos \theta\right)
$$

where the incident X-ray wavelength (1.54 $\AA$ ) and crystalline factor $(0.94)$ are denoted as $\lambda$ and $k$, respectively, and the full width at half maximum (FWHM) of the peak and the Bragg angles are denoted as $\beta$ and $\theta$, respectively. The average crystalline size of the synthesized nanocomposites was approximately $16.43 \AA$. We concluded that the doping of $\mathrm{Cu} / \mathrm{La}$ atoms decreased the crystalline size of the prepared nanocomposites based on the literature.

\subsection{Surface Morphology and Topography Studies of Nanocomposites}

The $\mathrm{Cu} / \mathrm{La} / \mathrm{CeO}_{2} / \mathrm{GO}$ morphology and structures were studied by FE-SEM analysis (Figure $3 \mathrm{a}, \mathrm{b}$ ). The analysis revealed that the hydrothermal synthesis methods caused the nanocomposites of $\mathrm{Cu} / \mathrm{La} / \mathrm{CeO}_{2} / \mathrm{GO}$ to grow into rod-like structures of uniform size.

TEM images of $\mathrm{Cu} / \mathrm{La} / \mathrm{CeO}_{2} / \mathrm{GO}$ nanocomposites are shown in Figure $3 \mathrm{c}, \mathrm{d}$. Figure $3 \mathrm{a}, \mathrm{b}$ presents TEM images of aggregated $\mathrm{Cu} / \mathrm{La} / \mathrm{CeO}_{2} / \mathrm{GO}$ nanocomposites showing that the particle size was small. In addition, the nanocomposites were irregular in shape, and their size was uneven. STEM-EDS elemental mapping showed the presence of all the doping materials, as shown in Figure $3 \mathrm{e}-\mathrm{h}$. It was concluded that the $\mathrm{Cu}, \mathrm{La}, \mathrm{Ce}$, and $\mathrm{C}$ in $\mathrm{Cu} / \mathrm{La} / \mathrm{CeO}_{2} / \mathrm{GO}$ nanocomposites overlapped. 

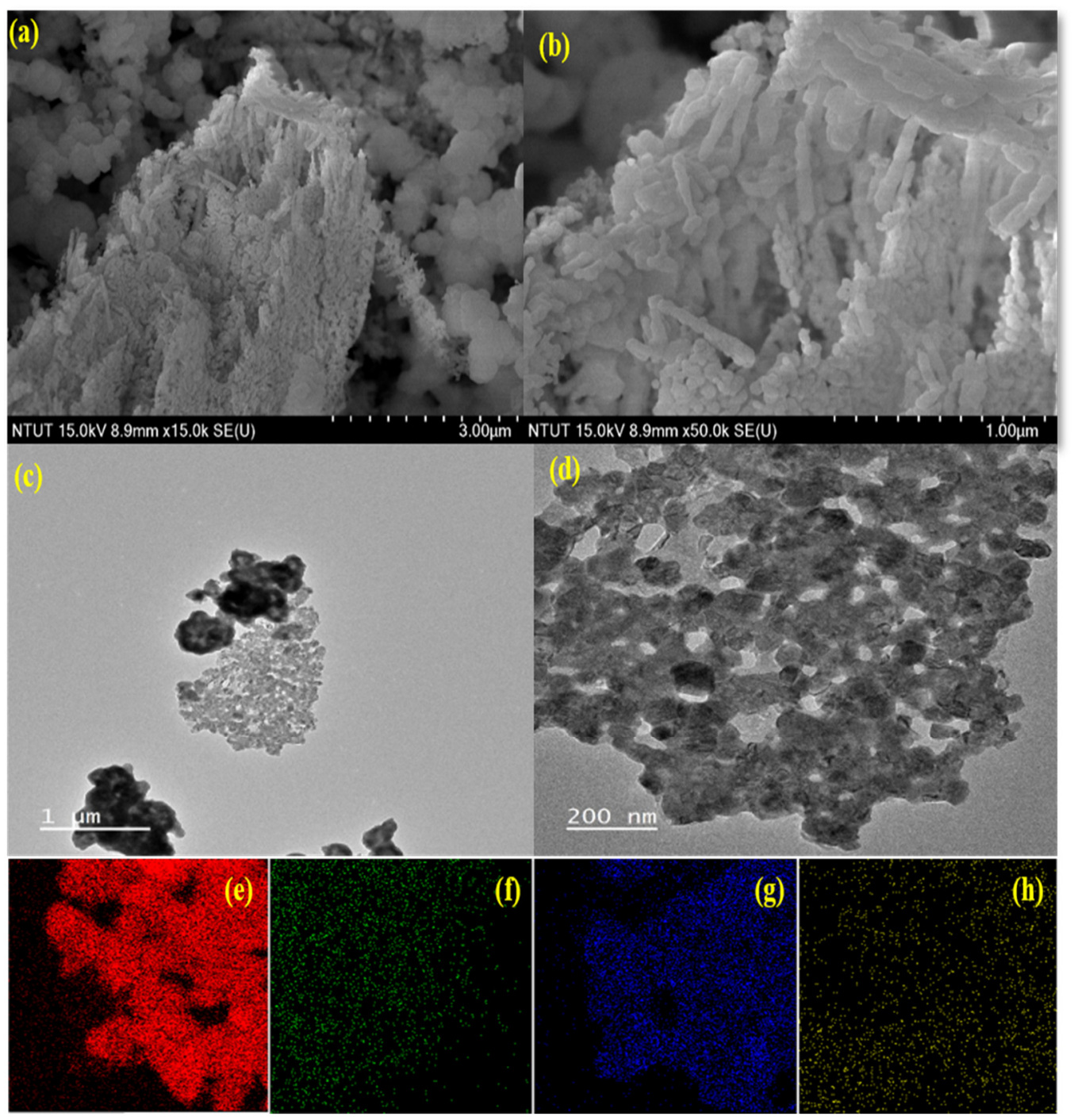

Figure 3. (a,b) Surface morphology of synthesized $\mathrm{Cu} / \mathrm{La} / \mathrm{CeO}_{2} / \mathrm{GO}$ nanocomposites. (c,d) TEM images for $\mathrm{Cu} / \mathrm{La} / \mathrm{CeO}_{2} / \mathrm{GO}$ nanocomposites, and elemental mapping for $\mathrm{Cu} / \mathrm{La} / \mathrm{CeO}_{2} / \mathrm{GO}$ nanocomposites: (e) $\mathrm{Ce}$, (f) $\mathrm{Cu},(\mathbf{g}) \mathrm{La}$, and (h) C.

\subsection{Nanocomposites Surface Chemistry Studies}

Figure 4 depicts the XPS survey and core-level high-resolution spectra of the $\mathrm{Cu} / \mathrm{La} /$ $\mathrm{CeO}_{2} / \mathrm{GO}$ nanocomposites. XPS is highly surface sensitive, which allows identification of unknown materials and oxidation states on the surfaces of nanocomposites. The XPS survey spectra clearly showed the presence of all the dopant materials in the nanocomposites (Figure 4a). The high-resolution XPS cerium compound Ce 3d core-level spectra are depicted in Figure $4 \mathrm{~b}$. The core-level spectra were deconvoluted into multiple peaks corresponding to the $\mathrm{Ce}^{4+}$ and $\mathrm{Ce}^{3+}$ oxidation states. These peaks at 887.7, 891.9, 900.3, 906.1, 910.7, and 918.2 $\mathrm{eV}$ represented the $\mathrm{Ce}^{4+}$-binding energies. In addition, the other binding energies of $\mathrm{Ce}^{3+}$ were at $884.4,889.4,903.1$, and $908.7 \mathrm{eV}$. The presence of $\mathrm{Ce}^{3+}$ sites on the surface of nanocomposites is crucial for the catalytic performance and regenerative capacity $\left(\mathrm{Ce}^{3+} \leftrightarrow \mathrm{Ce}^{4+}\right)$ of ceria nanoparticles [31-33]. Figure $4 \mathrm{c}$ presents the $\mathrm{Cu} 2 \mathrm{p}$ highresolution spectra of $\mathrm{Cu}$ core-level spectra. The $\mathrm{Cu} 2 \mathrm{p}_{3 / 2}$ and $\mathrm{Cu} 2 \mathrm{p}_{1 / 2}$ peaks at 935.5 and $954.9 \mathrm{eV}$, respectively, indicated the formation of the $\mathrm{Cu}^{+}\left(\mathrm{Cu}_{2} \mathrm{O}\right)$ oxidation state in the nanocomposites. Concurrently, the $\mathrm{Cu}^{2+}$ oxidation peaks also formed at 942.1, 946.9, 960.5 , and $966.2 \mathrm{eV}$, indicating the presence of the $\mathrm{Cu}^{2+}(\mathrm{CuO})$ oxidation state. The results revealed that the copper was present in two forms $\left(\mathrm{CuO}\right.$ and $\left.\mathrm{Cu}_{2} \mathrm{O}\right)$ of oxidation states in the 
nanocomposites. Figure $4 \mathrm{~d}$ also depicts the high-resolution La $3 \mathrm{~d}$ core-level spectra. These core-level spectra were deconvoluted into four peaks, all of which originated from the spinorbital splitting of the $\mathrm{La} 3 \mathrm{~d}_{5 / 2}$ and $\mathrm{La} 3 \mathrm{~d}_{3 / 2}$ states of $\mathrm{La}^{3+}$ oxidation. Figure 4 e depicts the high-resolution deconvoluted spectra of $\mathrm{C} 1 \mathrm{~s}$ for $\mathrm{Cu} / \mathrm{La} / \mathrm{CeO}_{2} / \mathrm{GO}$ nanocomposites, which had four oxygen-related functional groups at 285.8, 287.02, 288.78, and $289.5 \mathrm{eV}$. These oxygen-related functional groups were attributed to the $\mathrm{C}-\mathrm{O}$ (hydroxyl), $\mathrm{C}=\mathrm{O}$ (carbonyl), $\mathrm{O}-\mathrm{C}=\mathrm{O}$ (carboxylic acid), and carbonate bonds, respectively [34-38]. Moreover, the C-C (aromatic) and $\pi-\pi$ interaction bonds were also present at 284.6 and $290.3 \mathrm{eV}$, respectively.
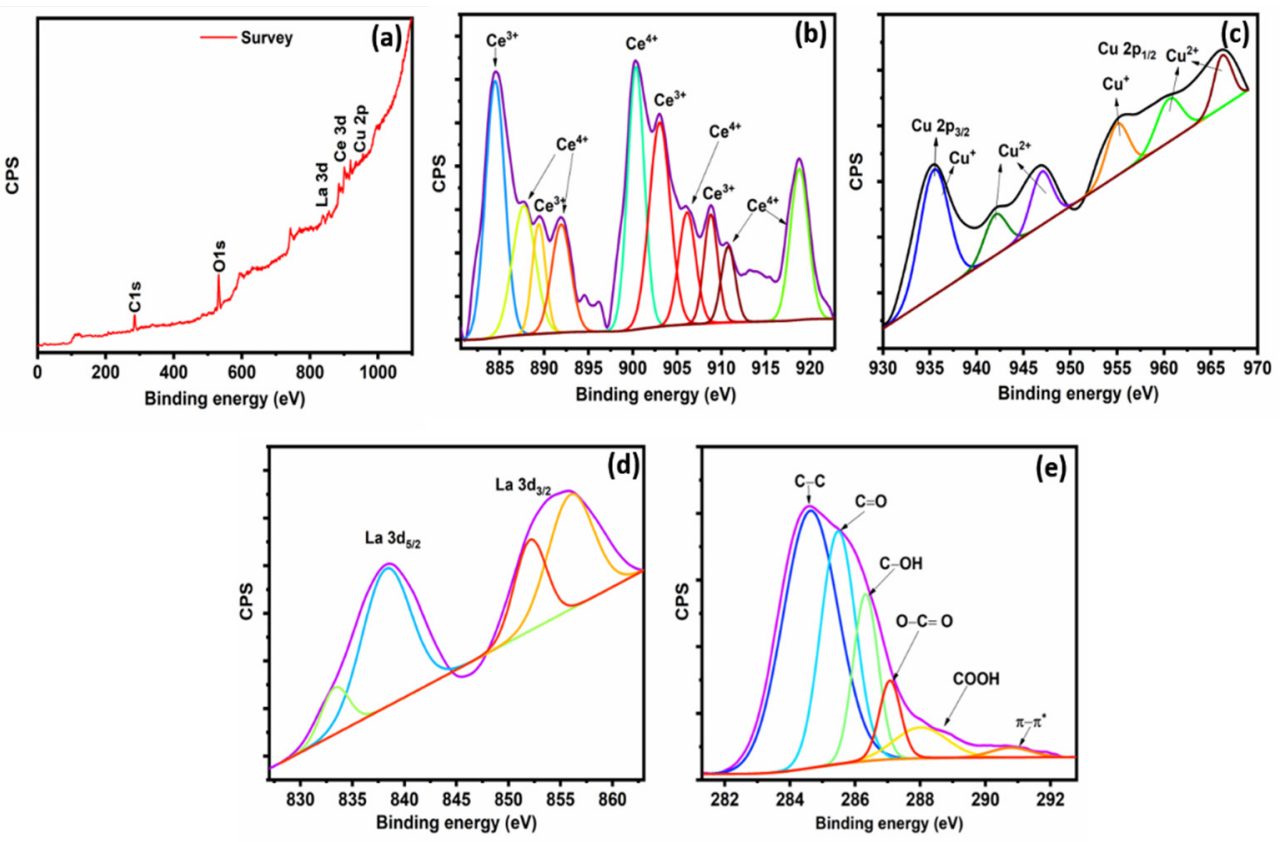

Figure 4. (a) The survey XPS spectrum; high-resolution XPS core-level spectra, (b) Ce 3d, (c) Cu 2p, (d) La 3d, and (e) C 1s spectra, respectively.

\subsection{Photocatalytic Activity of Synthesized $\mathrm{Cu} / \mathrm{La} / \mathrm{CeO}_{2} / \mathrm{GO}$ Nanocomposites}

The photocatalytic degradation ability of the hydrothermally synthesized nanocomposites was studied via the degradation of organic pollutants. The photodegradation of harmful organic dyes such as RhB, SY, and CR with nanocomposites and catalyst alone required a long treatment time. Moreover, the degradation process did not occur in the absence of visible light (Figure $5 \mathrm{~b}$ ). The degradation efficiency of the nanocomposites was studied using RhB dye, and the results confirmed that under visible light, the catalyst had higher photocatalytic degradation efficiency. In addition, the degradation of the $\mathrm{RhB}$ dye solution by the nanocomposites was in the following order: pure $\mathrm{CeO}_{2}<\mathrm{CeO}_{2} / \mathrm{GO}<\mathrm{Cu} / \mathrm{La} / \mathrm{CeO}_{2}$ (Figure $\mathrm{S} 1$ in Supplementary Materials). Figure $5 \mathrm{a}$ depicts the analysis of the degradation path of $\mathrm{RhB}$ at the maximum wavelength of $550 \mathrm{~nm}[7,8]$. The maximum absorption intensity of the RhB decreased with increasing treatment time, indicating that the degradation percentage depended on the treatment time. The degradation percentage of the aqueous solution was calculated by using the following expression $[7,8]$ :

$$
\text { Degradation percentage }=\frac{\left(C_{0}-C_{t}\right)}{C_{0}} \times 100
$$

where the dye concentrations before and after treatment are denoted as $C_{0}$ and $C_{t}$. 

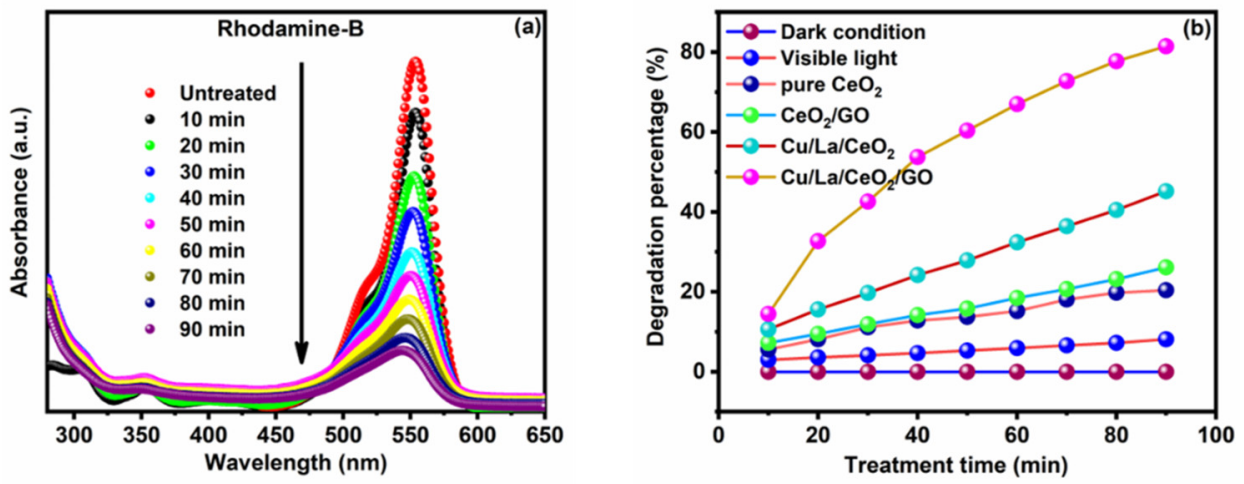

Figure 5. (a) Absorption spectrum and degradation percentage of Rhodamine B; (b) degradation percentage.

For a comparative study, the photocatalytic activity of the synthesized nanocomposites was also analyzed for two other toxic dyes, namely, SY and CR. The photocatalytic degradation of SY and CR organic dyes was observed using a UV-visible spectrophotometer at wavelengths of 482 and $500 \mathrm{~nm}$ (Figure 6a,c) (Figures S2 and S3), respectively [10,14]. The feature of $\mathrm{Cu} / \mathrm{La} / \mathrm{CeO}_{2} / \mathrm{GO}$ nanocomposite-assisted photodegradation is the shorter treatment time for the degradation of toxic organic dyes. Thus, it was found that the synthesized nanocomposites were highly efficient for the degradation of harmful organic dyes under visible-light irradiation (Figure $6 \mathrm{~b}, \mathrm{~d}$ ). Moreover, maximum mineralization was observed in the case of CR dye degradation within 50 min of treatment time. Therefore, because the synthesized nanocomposites tend to form a higher number of electron-hole pairs, higher numbers of hydroxyl and superoxide radicals were generated. These reactive radicals were the major factor in the degradation of the organic pollutants under visible light.
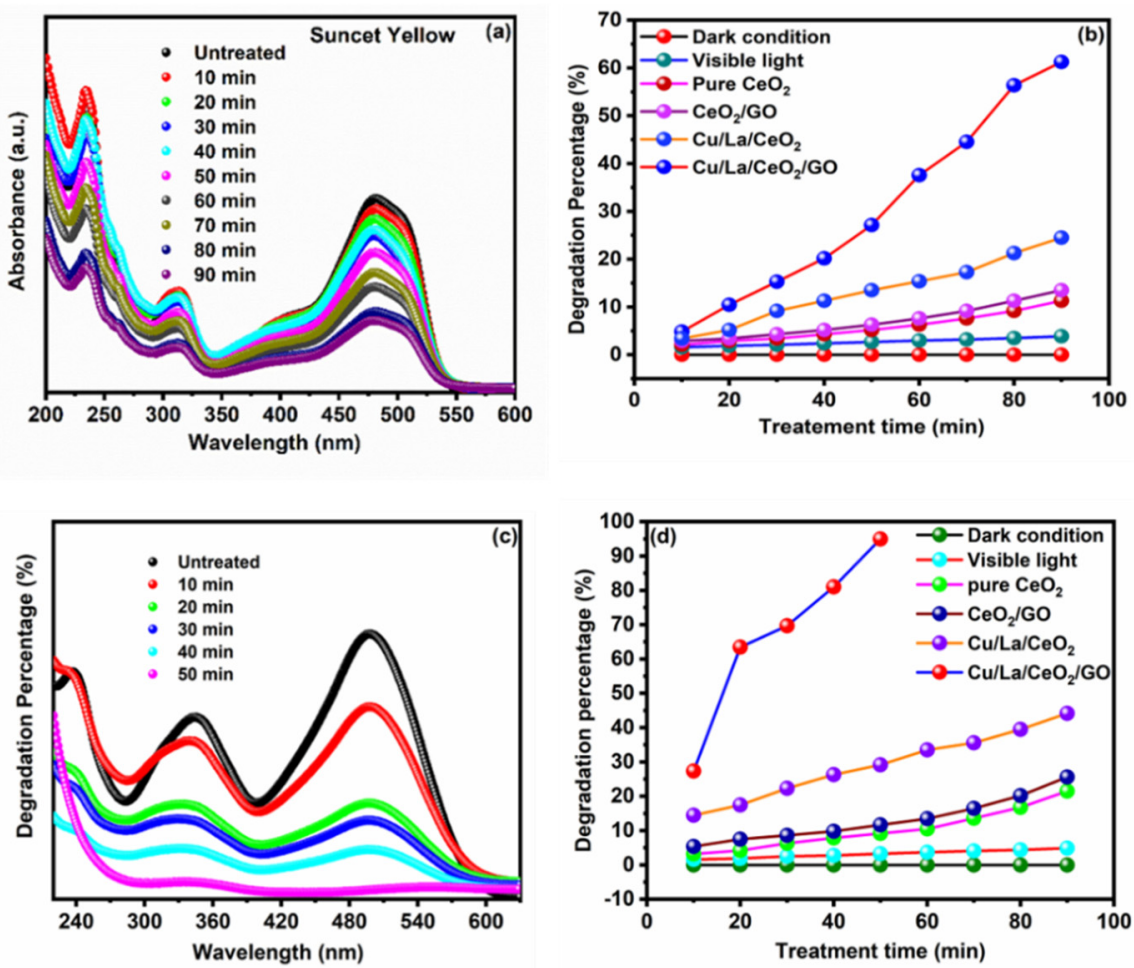

Figure 6. Photodegradation of SY and CR organic dyes using UV-vis spectra. (a,b) Absorption and degradation percentages of SY. (c,d) Absorption and degradation percentages of CR. 


\subsubsection{Photocatalytic Degradation Mechanisms}

The catalyst-assisted photocatalytic degradation reaction is an advanced oxidation process organized by a photocatalyst under visible-light irradiation. Pure $\mathrm{CeO}_{2}$ is a widebandgap material that is active under UV light and allows rapid recombination of photoinduced electron-hole pairs. These are the main reasons for decreases in the photocatalytic ability of the $\mathrm{CeO}_{2}$ nanoparticles. The $\mathrm{Ce}^{3+}$ ion, which is an excellent photocatalyst, is obtained from the introduction of oxygen vacancies in the $\mathrm{Ce}^{4+}$ lattice. Moreover, divalent or trivalent metal ion doping influenced the photocatalytic ability of $\mathrm{CeO}_{2}$, resulting in higher degradation activity. Hence, the doping of $\mathrm{Cu}^{2+} / \mathrm{La}^{3+}$ divalent and trivalent ions replaced the $\mathrm{Ce}^{4+}$ with $\mathrm{Ce}^{3+}$ in the $\mathrm{CeO}_{2}$ lattice and created surface defects in the form of oxygen vacancies, while the bandgap of $\mathrm{CeO}_{2}$ was also reduced, which increased the light absorption capability in the visible region [19-22,26]. These oxygen vacancies were largely responsible for the photocatalytic activity of the materials. Moreover, in $\mathrm{Cu} / \mathrm{La} / \mathrm{CeO}_{2} / \mathrm{GO}$ composites, GO acts as an electron transporter and acceptor because of its two-dimensional planar structure. Thus, the conduction band photogenerated electrons from $\mathrm{Cu} / \mathrm{La} / \mathrm{CeO}_{2}$ transferred to the target pollutant directly with the help of GO. Concurrently, the transferred electrons on GO directly interacted with surface oxygen to produce more superoxide radicals $\left(\mathrm{O}_{2}{ }^{\bullet-}\right)$. Additionally, the recombination rate of the photogenerated charge carrier in the $\mathrm{CeO}_{2}$ lattice was effectively restricted by the ions of the dopant materials. Therefore, the visible light on the surface of the photocatalyst absorbed more energy, resulting in electrons transferring from the valence band to the conduction band. Photogenerated electron-hole pairs were generated, as were electrons in the conduction band and positive holes in the valence band. The positive holes in the valence band reacted with $\mathrm{H}_{2} \mathrm{O}$ to generate more active hydroxyl radicals $\left(\mathrm{OH}^{\bullet}\right)$, while the excited electrons reacted with adsorbed oxygen to give superoxide radicals $\left(\mathrm{O}_{2}{ }^{\bullet-}\right)$. These reactive species were the major reason for the degradation of the targeted organic pollutants. Hence, these reactive species directly interacted with organic molecules, causing oxidation, and excitation occurred. Then the organic molecules transformed into non-hazardous organic molecules, water, and carbon dioxide. The photocatalytic degradation of organic effluents under visible light is expressed in the following equations [27-29]:

$$
\begin{gathered}
\mathrm{hv}+\mathrm{Cu} / \mathrm{Ce} / \mathrm{La} / \mathrm{GO} \rightarrow \mathrm{CeO}\left(\mathrm{h}^{+}+\mathrm{e}^{-}\right)+\mathrm{GO}\left(\mathrm{e}^{-}\right) \\
\mathrm{GO}\left(\mathrm{e}^{-}\right)+\mathrm{O}_{2} \rightarrow \mathrm{rGO}+\mathrm{O}_{2}^{\bullet-} \\
\mathrm{e}^{-}+\mathrm{O}_{2} \rightarrow \mathrm{O}_{2}^{\bullet-} \\
\mathrm{Ce}^{4+}+\mathrm{Cu}^{+}=\mathrm{Ce}^{3+}+\mathrm{Cu}^{2+} \\
\mathrm{Ce}^{4+}+\mathrm{La}^{3+} \rightarrow \mathrm{Ce}^{3+} \\
\mathrm{Ce}^{3+}+\mathrm{H}_{2} \mathrm{O}_{2} \rightarrow \mathrm{OH}^{\bullet}+\mathrm{OH}-\mathrm{Ce}^{4+} \\
\mathrm{Ce}^{4+}+\mathrm{H}_{2} \mathrm{O}_{2} \rightarrow \mathrm{Ce}^{3+}+\mathrm{OH}+\mathrm{H}_{2} \mathrm{O} \\
\mathrm{e}^{-}+\mathrm{O}_{2} \rightarrow \mathrm{O}_{2}^{\bullet-} \\
\mathrm{O}_{2}^{\bullet-}+\mathrm{OH}^{\bullet}+\text { organic pollutants } \rightarrow \mathrm{H}_{2} \mathrm{O}+\mathrm{CO}_{2} \text { (degradation of dyes) }
\end{gathered}
$$

\subsubsection{First-Order Kinetic Rate Constant Reaction}

The photocatalytic degradation of three different dyes was further evaluated with the help of a pseudo-first-order kinetic rate constant, which can be expressed by the following equation [9]:

$$
\ln \left(\mathrm{C} / \mathrm{C}_{0}\right)=-\mathrm{kt}
$$

where $C$ and $C_{0}$ are the concentrations of dyes before and after the treatment. The rate constant and treatment time are denoted as $\mathrm{k}$ and $\mathrm{t}$, respectively. Figure 7 shows the firstorder rate constant for the treatment time. The kinetic constants of RhB, SY, and CR were $-0.0114,-0.0188$, and $-0.0421 \mathrm{~min}$, with half-lives of $0.7018,0.7314$, and $0.7445 \mathrm{~min}^{-1}$, and 
the correlation coefficients $\left(R^{2}\right)$ were $0.9876,0.94062$, and 0.93102 , respectively. Therefore, the rate constant mainly depended on the treatment time because the treatment time increased with increases in the rate constant. As a result, the degradation of RhB, SY, and $C R$ was influenced by the generation of higher concentrations of various reactive species [9-13].

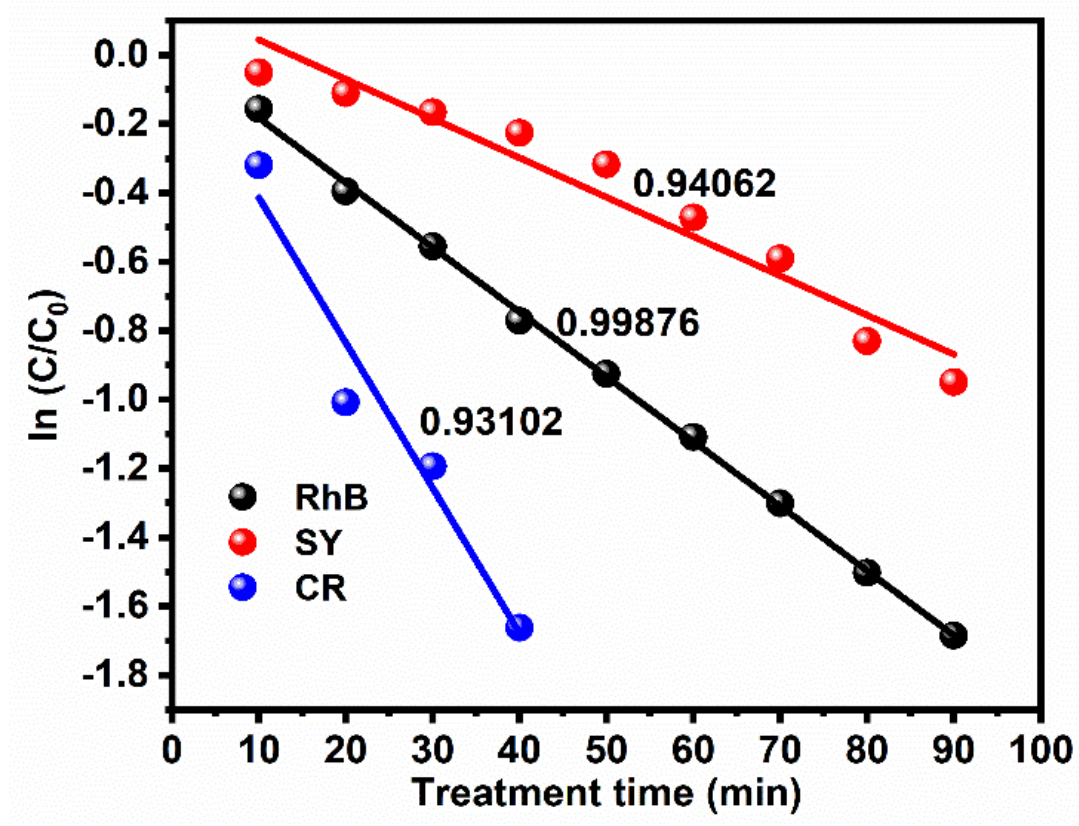

Figure 7. Pseudo-first-order kinetic rate constant for photocatalytic degradation of three different dyes.

\subsubsection{Radical-Trapping Experiments}

Photocatalyst-assisted degradation mainly depends on the generation of various reactive species, electrons, and holes. During the degradation reaction, the photocatalyst produces electron-hole pairs under visible-light irradiation, which generates reactive species such as $\mathrm{OH}^{\bullet}, \mathrm{H}_{2} \mathrm{O}_{2}, \mathrm{H}^{+}, \mathrm{O}$, and $\mathrm{O}_{2}{ }^{\bullet-}$. These active species play a vital role in the photocatalytic degradation process. Radical scavenger experiments were carried out using the nanocomposites to evaluate the types of reactive species that formed during the photocatalytic degradation process. In this experiment, $2 \mathrm{M}$ of ethylenediaminetetraacetic acid disodium salt $\left(\mathrm{Na}_{2} \mathrm{EDTA}\right)$ and isopropanol (IPA) were used as superoxide radicals and hydroxyl radical scavengers, respectively $[39,40]$. Figure 8 shows the results of the radical scavenger degradation of three different dyes. RhB, SY, and CR dye degradation was higher under visible-light irradiation in the absence of any radical scavengers. However, the degradation efficiency decreased in the presence of $\mathrm{Na}_{2}$ EDTA and IPA, respectively. The results strongly suggested that $\mathrm{OH}^{\bullet}$ was generated as the major active species for the degradation process, though the holes also contributed to the degradation process in the photocatalytic process. 


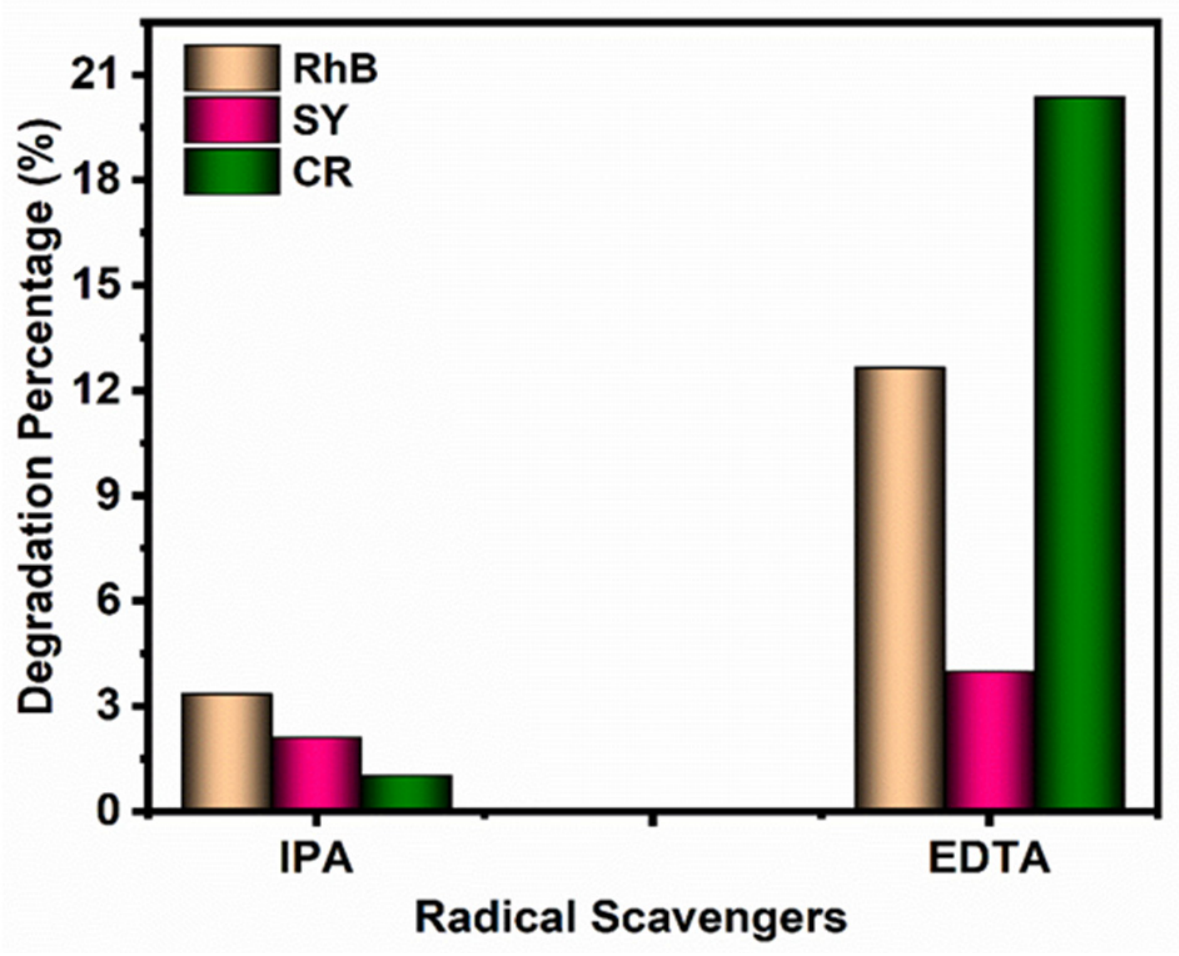

Figure 8. Degradation efficiency of radical scavengers' experiment.

\subsubsection{Nanocomposite Stability Studies}

To inspect the stability of the synthesized nanocomposites, a recycling experiment was conducted, and the results are depicted in Figure 9. Three successive cycles were conducted for $\mathrm{RhB}$ dye degradation under visible-light irradiation using $2 \mathrm{wt} \% \mathrm{Cu} / \mathrm{La} / \mathrm{CeO}_{2} / \mathrm{GO}$. The synthesized nanocomposite showed excellent efficiency (86\%) of RhB dye degradation even in the third cycle, demonstrating the stability of the nanocomposites.

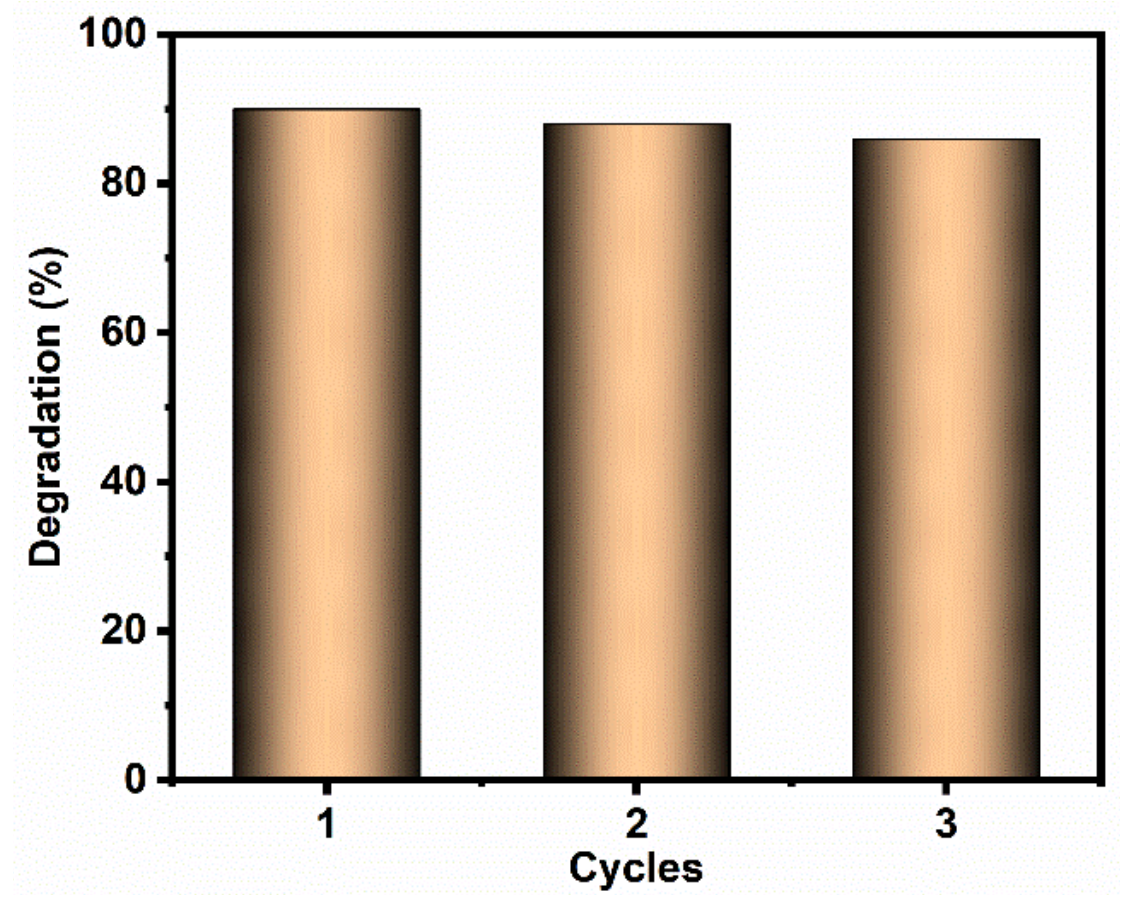

Figure 9. Photocatalytic stability studies of $\mathrm{Cu} / \mathrm{La} / \mathrm{CeO}_{2} / \mathrm{GO}$ nanocomposites. 


\section{Conclusions}

Cerium oxide $\left(\mathrm{CeO}_{2}\right)$ is a highly efficient photocatalyst, as it absorbs more visible light than $\mathrm{TiO}_{2}$ and $\mathrm{ZnO}$. The crystalline structure, surface morphology, and topography of the hydrothermally synthesized nanocomposites were studied. Cerium oxide was engineered by doping with $\mathrm{Cu}$ and $\mathrm{La}$ metal ions to increase visible-light absorption. Moreover, the efficiencies of the photocatalytic degradation of RhB, SY, and CR organic dyes were $80 \%$ $(\mathrm{RhB}), 60 \%$ (SY), and 95\% (CR) with treatment times of 90, 90, and 50 min, respectively. The photocatalytic degradation was improved by doping the metal ions, as well as the graphene oxide, due to the higher electron mobility, high light absorption capability, and restrictions of electron-hole pair recombination. In this regard, higher amounts of various reactive radicals were generated, which facilitated the effective degradation of the organic compounds. Accordingly, the hydrothermally synthesized $\mathrm{Cu} / \mathrm{La} / \mathrm{CeO}_{2} / \mathrm{GO}$ nanocomposites appear to be promising photocatalysts for the degradation of toxic organic dyes in aqueous solution.

Supplementary Materials: The following are available online at https:/ /www.mdpi.com/article/ 10.3390/ma14206143/s1, Figure S1: (a-c) Absorption spectrum of Rhodamine-B dye for various catalysis with re-spect to treatment time, Figure S2: $(\mathbf{a}-\mathbf{c})$ Absorption spectrum of sunset yellow dye for various catalysis with respect to treatment time, Figure S3: (a-c) Absorption spectrum of cibacron red dye for various catalysis with respect to treatment time.

Author Contributions: Conceptualization, methodology, and writing - original draft preparation, D.V.; Funding acquisition, investigation, and editing, Y.F.; Formal analysis, software, and writingreview and editing, A.K.K.; Investigation, validation, and writing—review and editing, S.S.; Supervision, funding acquisition, investigation, and validation, T.-W.C. All authors have read and agreed to the published version of the manuscript.

Funding: This research work was supported by the Ministry of Science and Technology of Taiwan (MOST 109-2221-E-027-059 and 110-2221-E-027-041) and the National Taipei University of Technology - Nanjing University of Science and Technology, China Joint Research Program (NTUTNUST-106-02). The authors are grateful to the Precision Research and Analysis Centre of the National Taipei University of Technology for providing the instrument facilities.

Institutional Review Board Statement: Not applicable.

Informed Consent Statement: Not applicable.

Data Availability Statement: Data are contained within the article.

Conflicts of Interest: The authors declare no conflict of interest.

\section{References}

1. Cheng, T.; Sun, X.; Xian, T.; Yi, Z.; Li, R.; Wang, X.; Yang, H. Tert-butylamine/oleic acid-assisted morphology tailoring of hierarchical $\mathrm{Bi}_{4} \mathrm{Ti}_{3} \mathrm{O}_{12}$ architectures and their application for photodegradation of simulated dye wastewater. Opt. Mater. 2021, 112, 110781. [CrossRef]

2. Kouser, S.; Hezam, A.; Byrappa, K.; Khanum, S.A. Sunlight-assisted synthesis of cerium (IV) oxide nanostructure with enhanced photocatalytic activity. Optik 2021, 245, 167236. [CrossRef]

3. Thilagavathi, T.; Venugopal, D.; Thangaraju, D.; Marnadu, R.; Baskaran, P.; Mohd, I.; Mohd, S.; Mohd, U.; Al Faify, S. A facile co-precipitation synthesis of novel $\mathrm{WO}_{3} / \mathrm{NiWO}_{4}$ nanocomposite with improved photocatalytic activity. Mater. Sci. Semicond. Process. 2021, 133, 105970. [CrossRef]

4. Wang, Y.; Wang, H.; Yang, Y.; Xin, B. Magnetic $\mathrm{NiFe}_{2} \mathrm{O}_{4} 3 \mathrm{D}$ nanosphere photocatalyst: Glycerol-assisted microwave solvothermal synthesis and photocatalytic activity under microwave electrodeless discharge lamp. Ceram. Int. 2021, 47, 14594-14602. [CrossRef]

5. Hassani, A.; Soltani, R.D.C.; Karaca, S.; Khataee, A. Preparation of montmorillonite-alginate nano biocomposite for adsorption of a textile dye in aqueous phase: Isotherm, kinetic and experimental design approaches. J. Ind. Eng. Chem. 2015, 21, 1197-1207. [CrossRef]

6. Ma, D.; Yi, H.; Lai, C.; Liu, X.; Huo, X.; An, Z.; Yang, L. Critical review of advanced oxidation processes in organic wastewater treatment. Chemosphere 2021, 275, 130104. [CrossRef] [PubMed]

7. Saratale, R.G.; Saratale, G.D.; Chang, J.-S.; Govindwar, S.P. Bacterial decolorization and degradation of azo dyes: A review. J. Taiwan Inst. Chem. Eng. 2011, 42, 138-157. [CrossRef] 
8. Ya, K.; Meyyanathan, S.N.; Nageswara, R.R. Methods for the analysis of azo dyes employed in food industry. Food Chem. 2016, 192, 813-824.

9. Rovina, K.; Prabakaran, P.P.; Siddiquee, S.; Shaarani, S.M. Methods for the analysis of Sunset Yellow FCF (E110) in food and beverage products-a review. TrAC Trends Anal. Chem. 2016, 85, 47-56. [CrossRef]

10. Nagaraja, R.; Kottam, N.; Girija, C.R.; Nagabhushana, B.M. Photocatalytic degradation of Rhodamine B dye under UV/solar light using ZnO nanopowder synthesized by solution combustion route. Powder Technol. 2012, 215, 91-97. [CrossRef]

11. Merouani, S.; Hamdaoui, O.; Saoudi, F.; Chiha, M. Sonochemical degradation of Rhodamine B in aqueous phase: Effects of additives. Chem. Eng. J. 2010, 158, 550-557. [CrossRef]

12. Ghoneim, M.M.; El-Desoky, H.S.; Zidan, N.M. Electro-Fenton oxidation of Sunset Yellow FCF azo-dye in aqueous solutions. Desalination 2011, 274, 22-30. [CrossRef]

13. Rajamanickam, D.; Shanthi, M. Photocatalytic degradation of an azo dye Sunset Yellow under UV-A light using TiO $2 / \mathrm{CAC}$ composite catalysts. Spectrochim. Acta Part A Mol. Biomol. Spectrosc. 2014, 128, 100-108. [CrossRef] [PubMed]

14. Pinheiro, A.C.; Bernardino, T.S.; Junior, F.E.; Lanza, M.R.; Barros, W.R. Enhanced electrodegradation of the Sunset Yellow dye in acid media by heterogeneous Photoelectro-Fenton process using $\mathrm{Fe}_{3} \mathrm{O}_{4}$ nanoparticles as a catalyst. J. Environ. Chem. Eng. 2020, 8, 103621. [CrossRef]

15. Jia, Z.; Liang, S.; Zhang, W.; Wang, W.; Yang, C. Heterogeneous photo Fenton-like degradation of cibacron brilliant red 3B-A dye using amorphous $\mathrm{Fe}_{78} \mathrm{Si}_{9} \mathrm{~B}_{13}$ and $\mathrm{Fe}_{73.5} \mathrm{Si}_{13.5} \mathrm{~B}_{9} \mathrm{Cu}_{1} \mathrm{Nb}_{3}$ alloys: The influence of adsorption. J. Taiwan Inst. Chem. Eng. 2017, 71, 128-136. [CrossRef]

16. Liu, L.; Chen, Z.; Zhang, J.; Shan, D.; Wu, Y.; Bai, L.; Wang, B. Treatment of industrial dye wastewater and pharmaceutical residue wastewater by advanced oxidation processes and its combination with nanocatalysts: A review. J. Water Process. Eng. J. Water Process. Eng. 2021, 42, 102122. [CrossRef]

17. Bilińska, L.; Gmurek, M. Novel trends in AOPs for textile wastewater treatment. Enhanced dye by-products removal by catalytic and synergistic actions. Water Resour. Ind. 2021, 26, 100160. [CrossRef]

18. Kumar, M.J.K.; Kalathi, J.T. Low-temperature sonochemical synthesis of high dielectric Lanthanum doped Cerium oxide nanopowder. J. Alloys Compd. 2018, 748, 348-354. [CrossRef]

19. Tinwala, H.; Shah, P.; Siddhapara, K.; Shah, D.; Menghani, J. Investigation of ionic conductivity of lanthanum cerium oxide nano crystalline powder synthesized by co precipitation method. J. Cryst. Growth 2016, 452, 54-56. [CrossRef]

20. Ranjith, K.S.; Dong, C.-L.; Lu, Y.-R.; Huang, Y.-C.; Chen, C.-L.; Saravanan, P.; Asokan, K.; Kumar, R.T.R. Evolution of visible photocatalytic properties of $\mathrm{Cu}$-doped $\mathrm{CeO}_{2}$ nanoparticles: Role of $\mathrm{Cu}^{2+}$-mediated oxygen vacancies and the mixed-valence states of Ce ions. ACS Sustain. Chem. Eng. 2018, 6, 8536-8546. [CrossRef]

21. Rostami, M. Photodecomposition and adsorption of hazardous organic pollutants by Ce-doped $\mathrm{ZnO@} \mathrm{Ce-doped} \mathrm{TiO} 2-\mathrm{N} / \mathrm{S}-\mathrm{dual}$ doped RGO ternary nano-composites photocatalyst for water remediation. J. Mol. Struct. 2019, 1185, 191-199. [CrossRef]

22. Mai, H.; Zhang, D.; Shi, L.; Yan, T.; Li, H. Highly active $\mathrm{Ce}_{1-x} \mathrm{Cu}_{\mathrm{x}} \mathrm{O}_{2}$ nanocomposite catalysts for the low temperature oxidation of CO. Appl. Surf. Sci. 2011, 257, 7551-7559. [CrossRef]

23. Zhang, D.; Mai, H.; Huang, L.; Shi, L. Pyridine-thermal synthesis and high catalytic activity of $\mathrm{CeO}_{2} / \mathrm{CuO} / \mathrm{CNT}$ nanocomposites. Appl. Surf. Sci. 2010, 256, 6795-6800. [CrossRef]

24. Zhang, D.; Qian, Y.; Shi, L.; Mai, H.; Gao, R.; Zhang, J.; Yu, W.; Cao, W. Cu-doped $\mathrm{CeO}_{2}$ spheres: Synthesis, characterization, and catalytic activity. Catal. Commun. 2012, 26, 164-168. [CrossRef]

25. Li, Y.; Cai, Y.; Xing, X.; Chen, N.; Deng, D.; Wang, Y. Catalytic activity for CO oxidation of Cu-CeO 2 composite nanoparticles synthesized by a hydrothermal method. Anal. Methods 2015, 7, 3238-3245. [CrossRef]

26. Lim, W.F.; Cheong, K.Y. Oxygen vacancy formation and annihilation in lanthanum cerium oxide as a metal reactive oxide on 4H-silicon carbide. Phys. Chem. Chem. Phys. 2014, 16, 7015-7022. [CrossRef]

27. Velliyan, S.; Rajendran, V. Study on the effect of $\mathrm{Ce}^{3+}$ doping on structural, morphological and optical properties of CuO nanoparticles synthesized via combustion technique. Phys. B Condens. Matter 2021, 613, 413015. [CrossRef]

28. Deus, R.; Cortés, J.; Ramirez, M.; Ponce, M.A.; Andres, J.; Rocha, L.; Longo, E.; Simões, A. Photoluminescence properties of cerium oxide nanoparticles as a function of lanthanum content. Mater. Res. Bull. 2015, 70, 416-423. [CrossRef]

29. Chahal, S.; Singh, S.; Kumar, A.; Kumar, P. Oxygen-deficient lanthanum doped cerium oxide nanoparticles for potential applications in spintronics and photocatalysis. Vacuum 2020, 177, 109395. [CrossRef]

30. Sakthinathan, S.; Keyan, A.K.; Rajakumaran, R.; Chen, S.M.; Chiu, T.W.; Dong, C.; Vinothini, S. Synthesis of N-rGOMWCNT $/ \mathrm{CuCrO}_{2}$ Catalyst for the Bifunctional Application of Hydrogen Evolution Reaction and Electrochemical Detection of Bisphenol-A. Catalysts 2021, 11, 301. [CrossRef]

31. Vinothkumar, G.; Arunkumar, P.; Mahesh, A.; Dhayalan, A.; Babu, K.S. Size-and defect-controlled anti-oxidant enzyme mimetic and radical scavenging properties of cerium oxide nanoparticles. New J. Chem. 2018, 42, 18810-18823. [CrossRef]

32. Janoš, P.; Henych, J.; Pfeifer, J.; Zemanová, N.; Pilařová, V.; Milde, D.; Opletal, T.; Tolasz, J.; Malý, M.; Štengl, V. Nanocrystalline cerium oxide prepared from a carbonate precursor and its ability to breakdown biologically relevant organophosphates. Environ. Sci. Nano 2017, 4, 1283-1293. [CrossRef]

33. Eloirdi, R.; Cakir, P.; Huber, F.; Seibert, A.; Konings, R.; Gouder, T. X-ray photoelectron spectroscopy study of the reduction and oxidation of uranium and cerium single oxide compared to (U-Ce) mixed oxide films. Appl. Surf. Sci. 2018, 457, 566-571. [CrossRef] 
34. Sun, H.; Zelekew, O.A.; Chen, X.; Guo, Y.; Kuo, D.-H.; Lu, Q.; Lin, J. A noble bimetal oxysulfide CuVOs catalyst for highly efficient catalytic reduction of 4-nitrophenol and organic dyes. RSC Adv. 2019, 9, 31828-31839. [CrossRef]

35. Chen, R.X.; Zhu, S.L.; Mao, J.; Cui, Z.D.; Yang, X.J.; Liang, Y.Q.; Li, Z.Y. Synthesis of $\mathrm{CuO} / \mathrm{Co}_{3} \mathrm{O}_{4}$ coaxial heterostructures for efficient and recycling photodegradation. Int. J. Photoenergy 2015, 2015, 183468. [CrossRef]

36. Yadav Anuja, A.; Vaibhav, C.; Lokhande Ravindra, N.; Chandrakant, D. Amperometric $\mathrm{CO}_{2}$ gas sensor based on interconnected web-like nanoparticles of $\mathrm{La}_{2} \mathrm{O}_{3}$ synthesized by ultrasonic spray pyrolysis. Microchim. Acta 2017, 184, 3713-3720. [CrossRef]

37. Hu, S.; Chi, B.; Pu, J.; Jian, L. Novel heterojunction photocatalysts based on lanthanum titanate nanosheets and indium oxide nanoparticles with enhanced photocatalytic hydrogen production activity. J. Mater. Chem. A 2014, 2, 19260-19267. [CrossRef]

38. Mutharani, B.; Ranganathan, P.; Chen, S.-M.; Karuppiah, C. Simultaneous voltammetric determination of acetaminophen, naproxen, and theophylline using an in-situ polymerized poly (acrylic acid) nanogel covalently grafted onto a carbon black/ $\mathrm{La}_{2} \mathrm{O}_{3}$ composite. Microchim. Acta 2019, 186, 651. [CrossRef]

39. El-Berry, M.F.; Sadeek, S.A.; Abdalla, A.M.; Nassar, M.Y. Microwave-assisted fabrication of copper nanoparticles utilizing different counter ions: An efficient photocatalyst for photocatalytic degradation of safranin dye from aqueous media. Mater. Res. Bull. 2021, 133, 111048. [CrossRef]

40. Ghorai, K.; Panda, A.; Bhattacharjee, M.; Mandal, D.; Hossain, A.; Bera, P.; Seikh, M.; Gayen, A. Facile synthesis of $\mathrm{CuCr}_{2} \mathrm{O}_{4} / \mathrm{CeO}_{2}$ nanocomposite: A new Fenton like catalyst with domestic LED light assisted improved photocatalytic activity for the degradation of RhB, MB and MO dyes. Appl. Surf. Sci. 2021, 536, 147604. [CrossRef] 